\title{
A Study of Information Exchange for Architect \& Engineer BIM Design under Low Impact Development Method
}

\author{
Sangmin Park ${ }^{1}$ and Reeho Kim ${ }^{1 *}$ \\ ${ }^{1}$ Damwon Co., Ltd. \\ *Korea Institute of Civil Engineering and Building Technology (KICT) \\ ${ }^{1}$ sangmin.park@dwbc.co.kr, rhkim@kict.re.kr
}

\begin{abstract}
Collaboration of each division and BIM data continuity have been discussed continuously along with the introduction of the BIM design method in the construction sector and there is an increasing demand for design data analysis and simulation rather than simple design modeling. However, difficulties regarding data exchange using different software from different divisions in BIM design arose early in the implementation stage of BIM. Thus, designs have been conducted bused only on the exchange between shape information and partial attributes As a result of suggesting the data exchange method for design collaboration of BIM design in the civil engineering sector and simulating the analysis process with applieation of Dow Impact Development (LID) in BIM design, smooth collaboration was maintained@long with continuity of data between BIM design software and BIM-basea analysis was subsequently carried out.
\end{abstract}

Keywords: LID, BIM, Data Exchange, GIS

\section{Introduction}

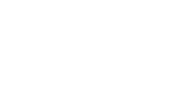

In the beginning of the $2000 \mathrm{~s}$, the concept of 3D object oriented modeling was implemented in the consurftion sector and design/construction based on 3D Information Model was introduced as an efficient plan to reduce errors and costs. However, contrary to high expectations in the early stages of implementation, the expectations are being significantly lowered after application of BIM to actual tasks. There are several reasons why BIM is not achieving more than expected in general architect \& engineer design, but the understanding of the vanous requirements for BIM, not the existing construction design environment, is required first [1], and the emphasis must be on interoperability of data for collaboration that allows for BIM data utilization via linkage with AEC adjacent fields [2]. Thus, the research aims to suggest interoperability methods of architect \& engineering BIM data in general townhouse design and conduct analysis of BIM data based LID

\section{Study Location \& Method}

This study targeted the area near the Danao city of Compostela, Cebu, Philippines. The study area mean elevation is $10.0 \mathrm{~m}$, land slope running from the northwest to the southeast, and 10-minute precipitation level is $177.08 \mathrm{~mm}$ from the IDF curve which is from the 1991 year Cebu Mactan Circumferential Road project.

* Corresponding author: Reeho Kim, Korea Institute of Civil Engineering and Building

Technology(KICT), Goyang 10223, Republic of Korea

E-mail:rhkim@kict.re.kr

Received April 22. 2016: Revised July 05. 2016

Accepted July 09. 2016 

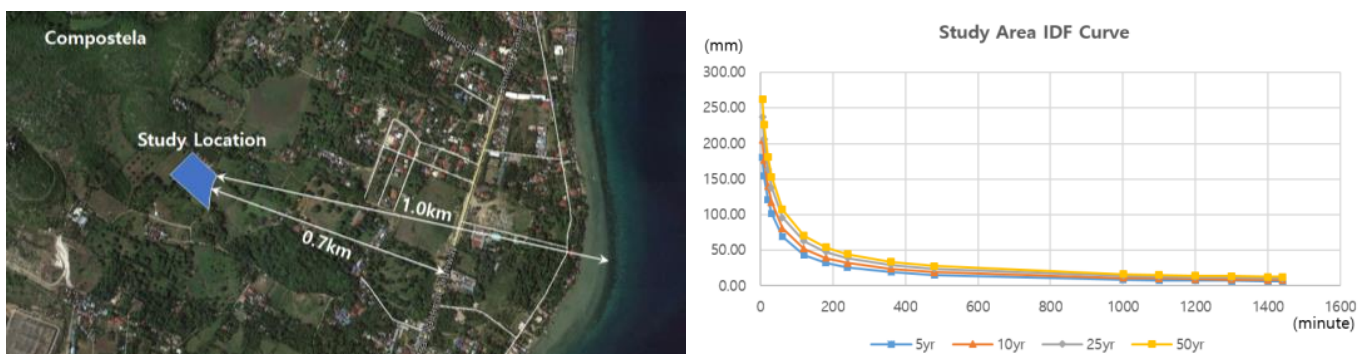

Figure 1. Study Location Map \& IDF Curve

\subsection{Study Method}

There are several kinds of BIM Software used in engineering and architecture, but the usage of Civil3D and Revit from Autodesk ${ }^{\circledR}$ is common. However, the generally discussed data exchange through IFC (Industry Foundation Classes) is not poss ble with these two software and thus, there was a need for collaboration using shape information converted to the *.dwg format or collaboration with viewer software such as Autodesk ${ }^{\circledR}$ Navisworks.

However, there is need for a full data exchange method because it is impossible for designers to engage in numerical design data review and collaboration across several design divisions based only on shape information, partial reconstruction of the analyzed data is required with every design change and the restrictions in quantity schedule work are clear. Although recently released civilengineering solutions support IFC $2 \times 4$, it is nothing more than a partial extension of shape information since it does not support exchanges regarding reconstruction of the original design database when importing IFC $2 \times 4$ files to other BIM solutions.

However, by printing out the attribute jnformation as text files, rearranging it in document format that is supported by collaborating software and automating these series of process, the limitations of software in different divisions were resolved and smooth collaboration between sector through BMI data continuity and design data format change was achieved. Also, each sectors can reduce their project budgets regarding the maintenance costs of unnecessary soltware needed for review of design data from other sectors. This-dissertation wishes to discuss the concept of codes designed for data exchange, simplified method of design data exchange that reduces data loss during the exchange and the process of low-impact development analysis based on the exchanged BIM data

\subsection{Information Exchange Problem}

Various methods are being tried out to ensure data compatibility of various construction divisions using the same or different BIM software platforms. Currently there 3 typical exchange methods; direct exchange within the same software platform acceptable for similar sector such as architecture, Structure, Mechanical and Electrical), compatibility supplementation using API (Application Program Interface) base Add-on software and data export/import based on the standard information exchange model [4]. 


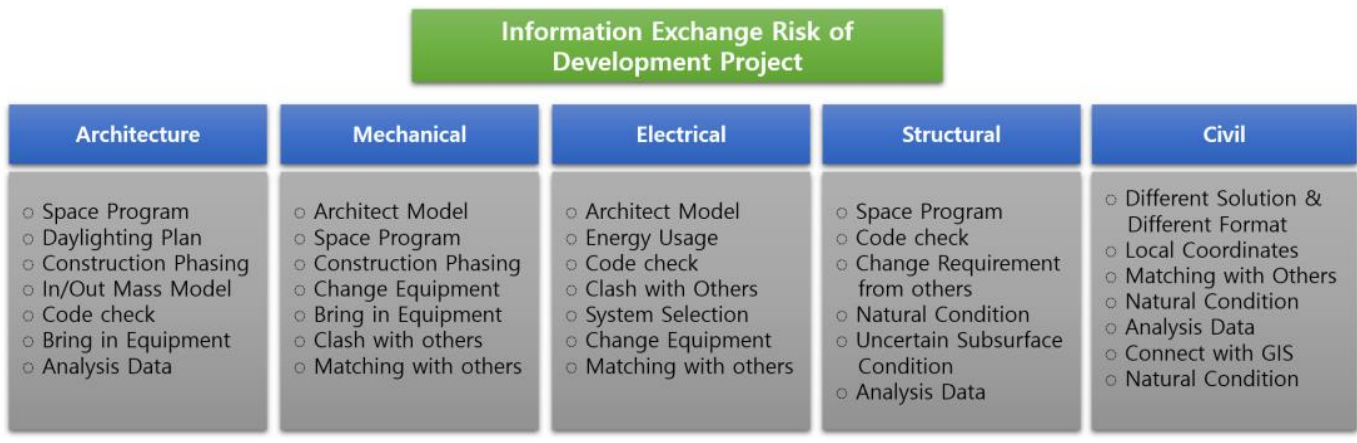

Figure 2. Information Exchange Risk of Development Project

However, problems of information exchange within the same BIM software platforms (such as limitations in file volume size and maximum design area) are continuously appearing and the BIM data compatibility problem between different software platforms gives rise to the discussion of a fundamental issue in BIM design that considers collaboration between different sectors as highly valuable. According to the data from a previous study which analyzed the reasons for design change in eight construction sites, $49 \%$ of the approved changes were caused by collaboration-related issues [5]. Thus, BIM collaboration is required, as much as BIM design os being primarily used to reduce errors/omissions and utilized for collaboration between owners and design firms. [6]

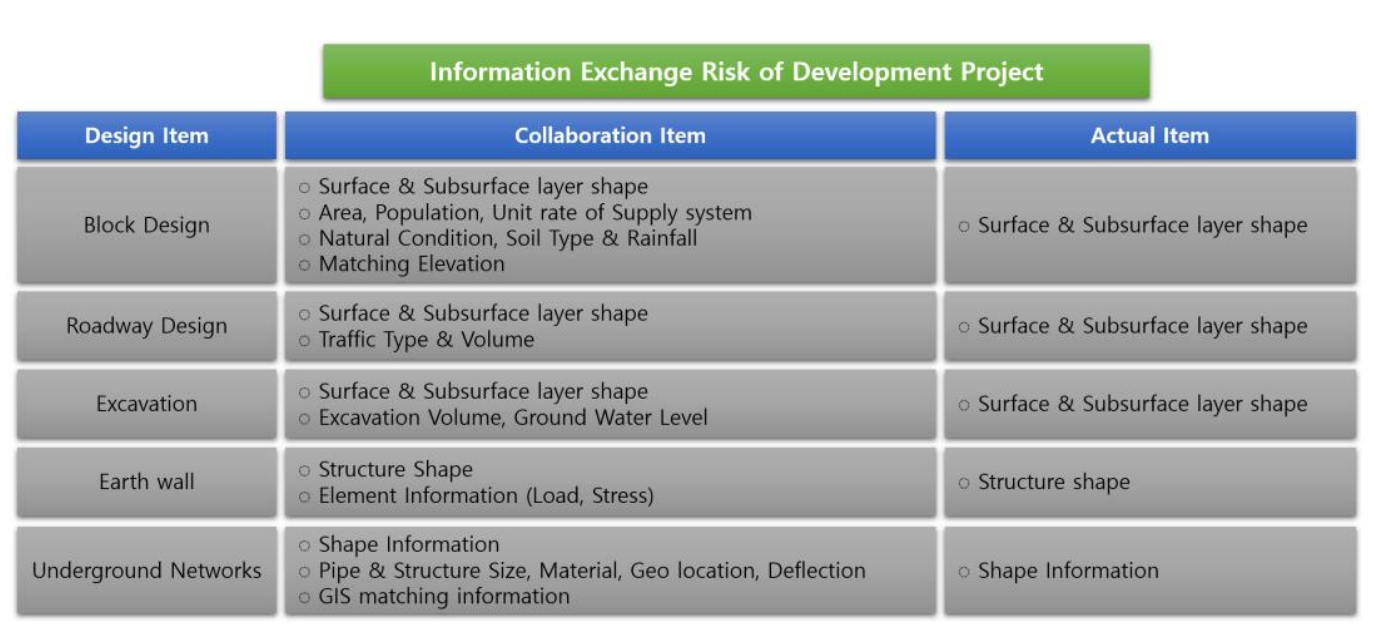

Figure 3. Information Exchange Item of Development Project

\subsection{Exchange Program Code}

In order for exchange of BIM data in an ongoing design process within the collaboration between the civil engineering and construction sectors, the data needs to be extracted in text format. Civil engineering surface shape data can be transferred to Revit ground element via LandXML or IFC format but it only shows surface data and does not contain ground information. Also subsurface pipes, fittings and other numerical data cannot be exchanged with each other. This issue is a concern when using the IFC $2 \times 4$ schema which does not support civil engineering entities and also when developing a schema that is not available in the current commercial BIM solution.

Also there is a need for extraction of attribute data (such as the starting point, ending point, diameter and ingredients of subsurface pipes) into text format (*.csv), which is the most basic format for defining entity attributes and can be identified with commas. Since Autodesk Civil3D organizes and shows the gathered data in panorama view, the 
information was extracted into Microsoft Excel or text format (*.csv). Additionally, the extracted data can be converted into Revit element and edited through Schedule.

The extracted data was available for use while tracking changes regardless of the distance, by saving the data in a SVN (Subversion) local server or uploading it on a Cloud server, in which the VCS (Version Control System) was applied to the settings for collaborators in remote areas. Also, files with errors that were uploaded could be restored with the previous file. Using C\#-based Autodesk Revit SDK command, the extracted underground coordinate data were defined as new points P1 and P2 (these points refer to the coordinates of the starting and ending points) via parsing, according to the comma, from the text format data as can be seen below. Regarding this, the coordinate area in the construction sector is restrictive, with only $33 \mathrm{~km}$ (20 miles), and thus a Project Point must be set and the data that took out the Project Point distance from the original coordinate system in the civil engineering sector must be parsed

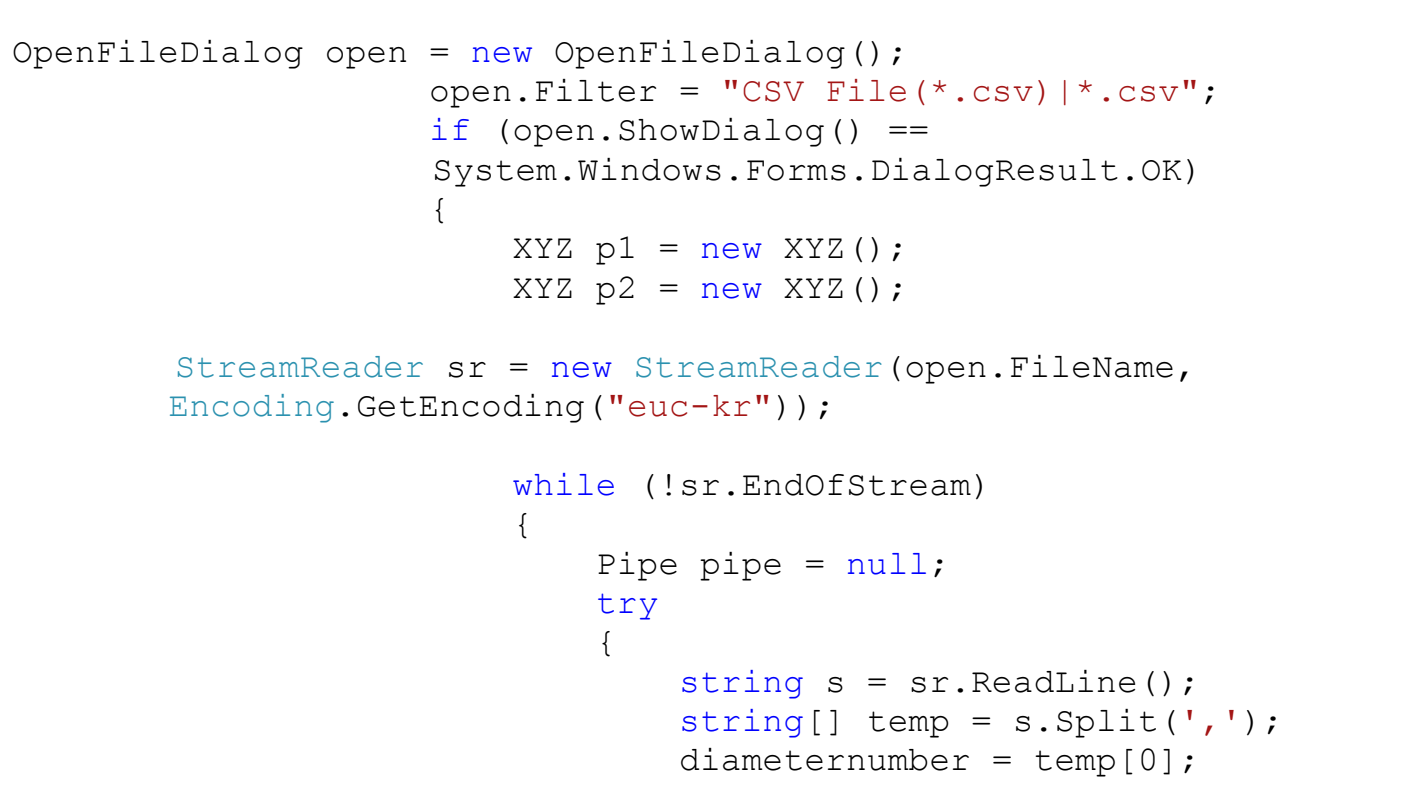

The location of the starting/ending points of the subsurface pipes were already designated $n$ the definitior above and thus the attribute will be defined by assigning titles to the pipe family defined in the design template and the definition regarding the diameter and thickness of the prpe will be carried out below.

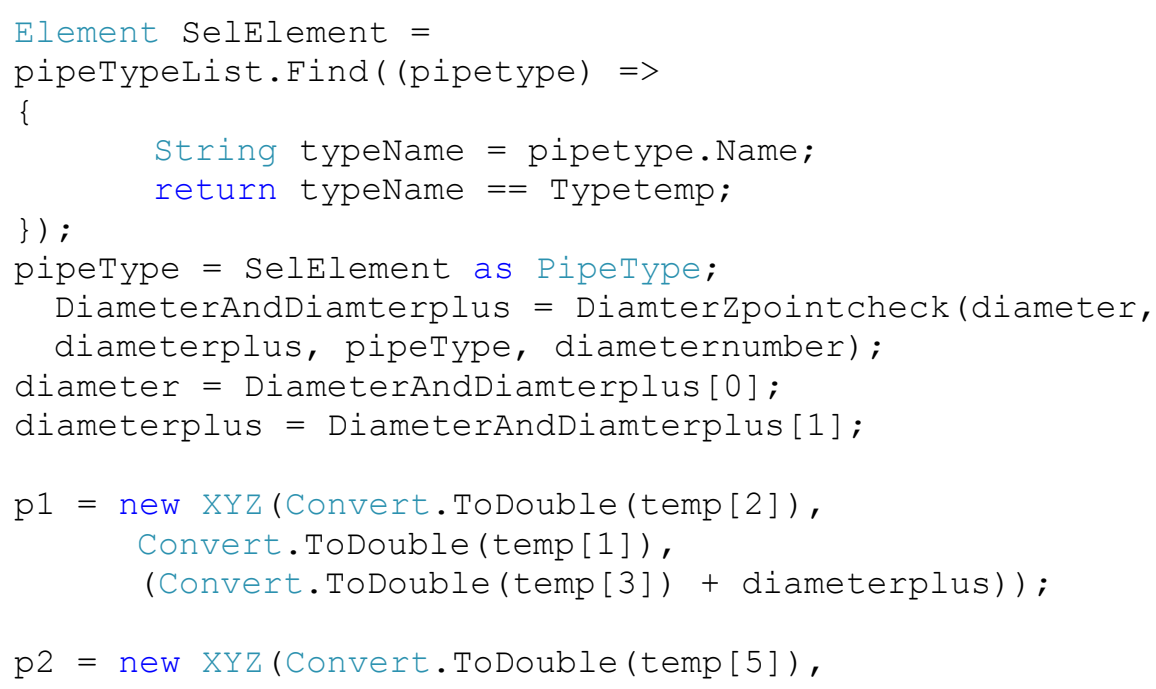




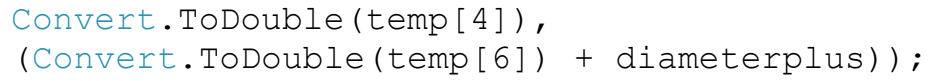

Additionally, by acquiring the $\mathrm{X}$, $\mathrm{Y}$ figures of the facility family (such as manholes, catch basin, reservoir and holding tank) in the same way as the pipe figures were found and the Civil3D model was transferred to Revit by arranging the family in designated locations and automatically imputing the $\mathrm{z}$ position via the family parameter. Subsequently, this process was defined as an icon in the User Interface Ribbon and the creation of the model was automated.

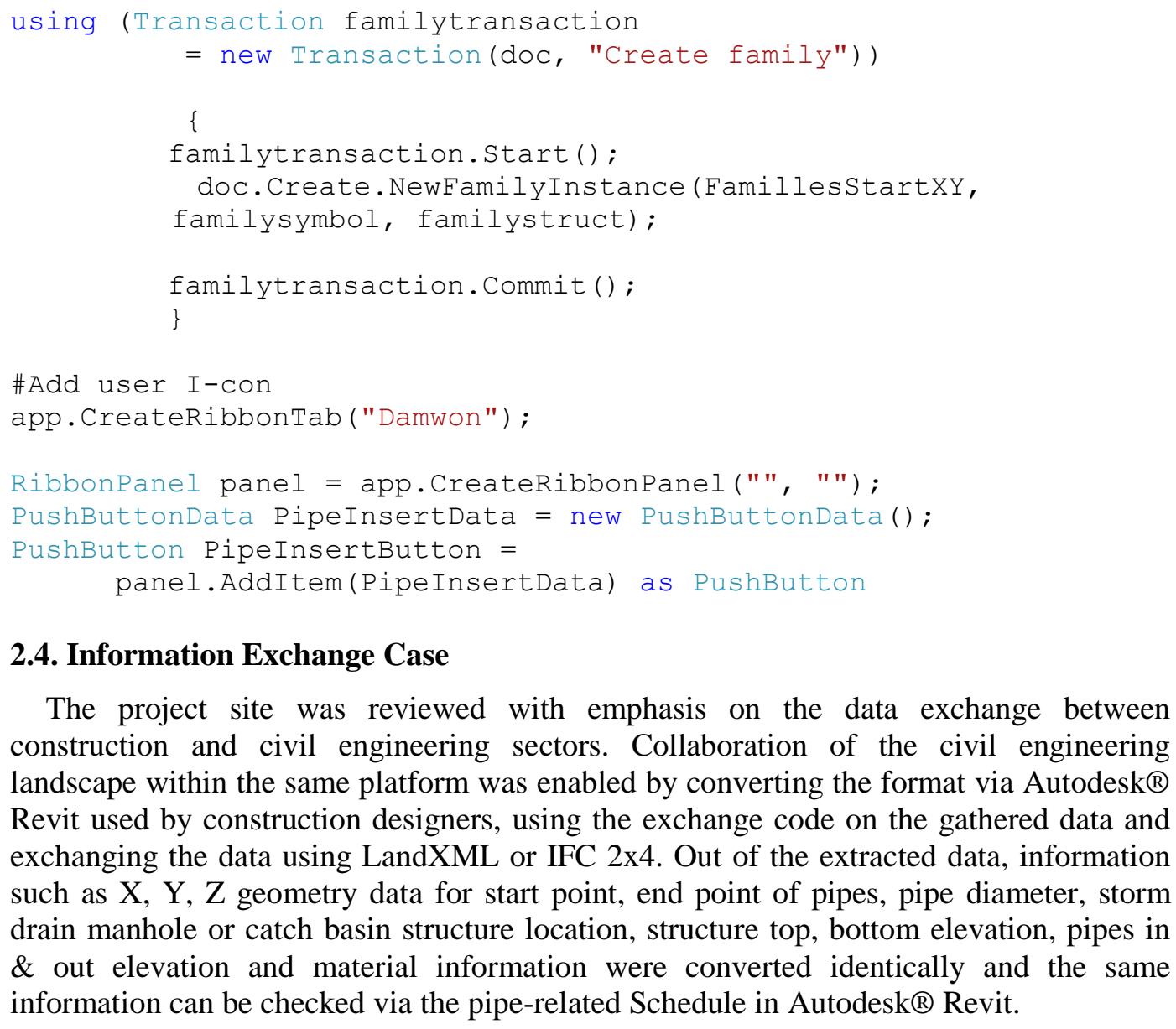

\subsection{Information Exchange Case}

The project site was reviewed win emphasis on the data exchange between construction and civil engineering sectors. Collaboration of the civil engineering landscape within the same platform was enabled by converting the format via Autodesk ${ }^{\circledR}$ Revit used by construction designers, using the exchange code on the gathered data and exchanging the data using LandXML or IFC $2 \times 4$. Out of the extracted data, information such as $\mathrm{X}, \mathrm{Y}, \mathrm{Z}$ geometry cata for start point, end point of pipes, pipe diameter, storm drain manhole or catch basm structure location, structure top, bottom elevation, pipes in $\&$ out elevation and material information were converted identically and the same information can becheeked via the pipe-related Schedule in Autodesk® Revit. 

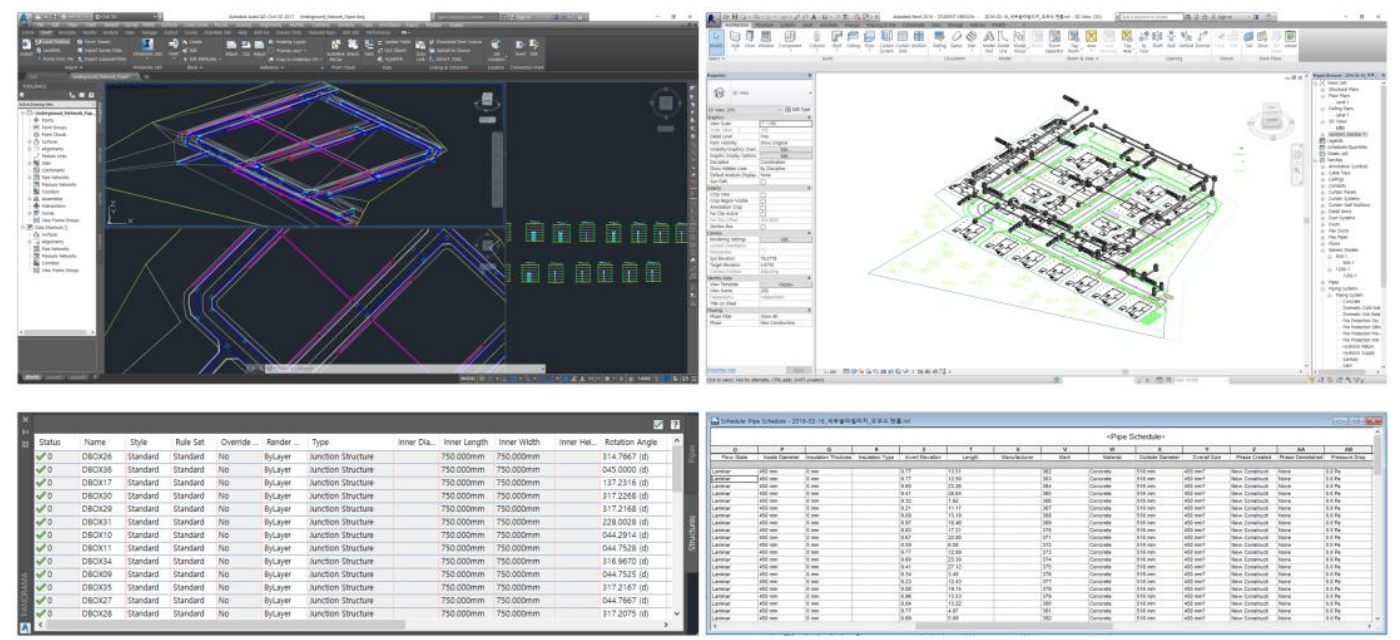

Figure 4. Design Information Exchange Case (Civil3D Pipes Panorama to Revit Pipe Schedule)

The designer was able to check the numerical point of contact through collaboration via data exchange and was able to prevent errors and misunderstandings between designconstruction. There was no data loss during the data exchange process between different platforms; the transfer of IFC data into ESRI® Arcmap GIS data through the data interoperability extension of ESRI in Autode $\mathrm{K} \otimes$, Revit anđ in Autodesk ${ }^{\circledR}$ Civil3D (via the GIS Export function of Storm and Sanitary Analysis) was achieved without data loss.

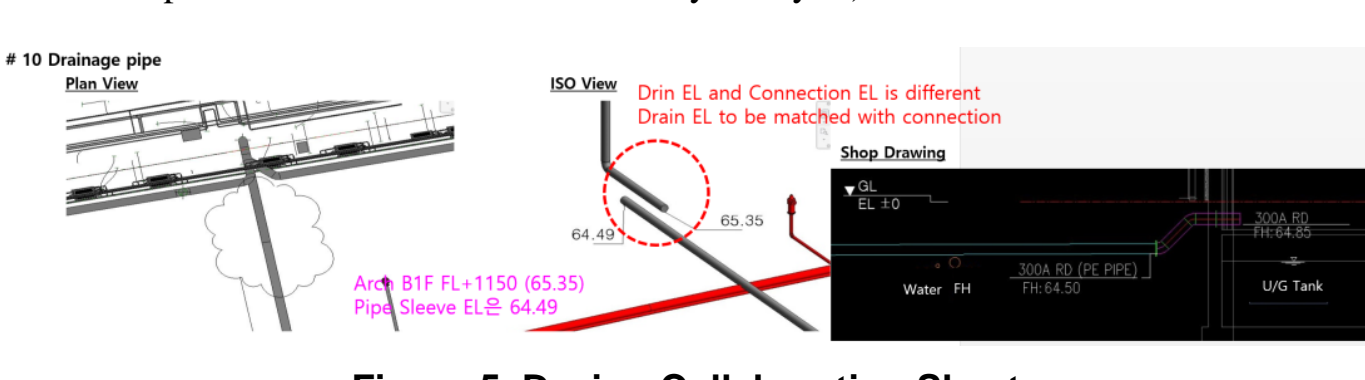

\section{Low Impact Development Analysis}

The interpreta $10 \mathrm{n}$ Software uses EPA-SWMM and Autodesk ${ }^{\circledR}$ Storm and Sanitary Analysis, which can be directly imported from Autodesk ${ }^{\circledR}$ Civil3D or GIS. The analytical model obta/ned drainage network, watershed characteristics data from BIM data and added the rainfall information of study site, which is distributed by center concentration time series of alternated block method from IDF curve.

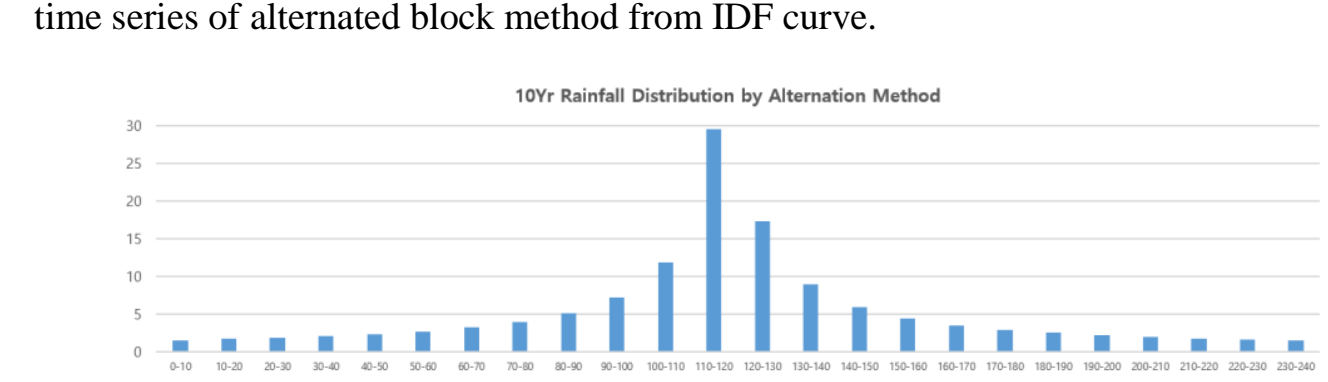

Figure 6. Rainfall Time Distribution 
General drainage network and underground detention basin was analyzed by using storm and sanitary analysis and LID elements such as permeable block, roof garden and rain garden was converted to and analyzed as EPA-SWMM, from Autodesk storm and sanitary analysis data without any data loss [3].

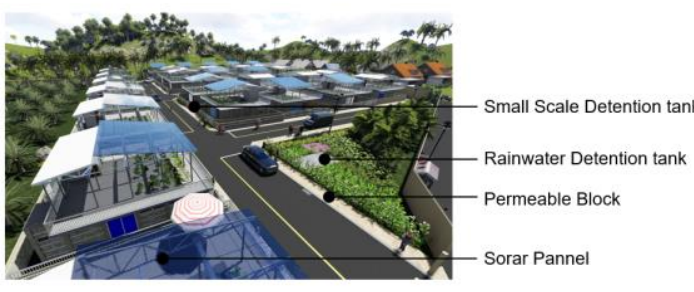

3D Simulation

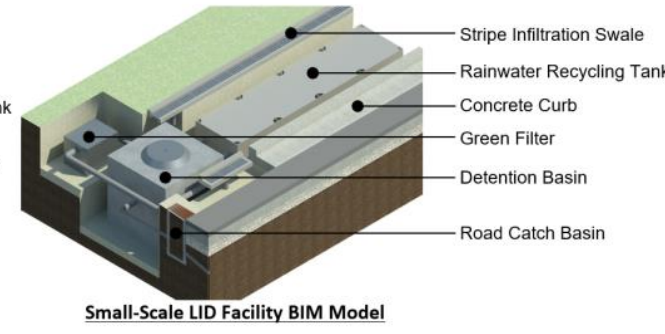

Small-Scale LID Facility BIM Model

Figure 7. Study Location Rendering Image and Small Scale LID Equipment for each Housing

The project site is composed $43.8 \%$ of housing area, $244 \%$ of pavement area and average curve number is 78.9. Ground water of housing, walkyvay and payement area to be stored in small scale detention basin of each housing, which is able to catch rain water. Each household tank capacity to be determined a $78 \mathrm{~m}^{2}$ of roof area which is catch rain water up to $0.05 \mathrm{~mm}$ to $0.1 \mathrm{~mm}$ in depth and capacity is determined 4 ton to 8 ton. The outflow portion of project site to be installed $5 \mathrm{~m}^{3}$ of detenfion tank which is determined by discharge flow of initial analysis

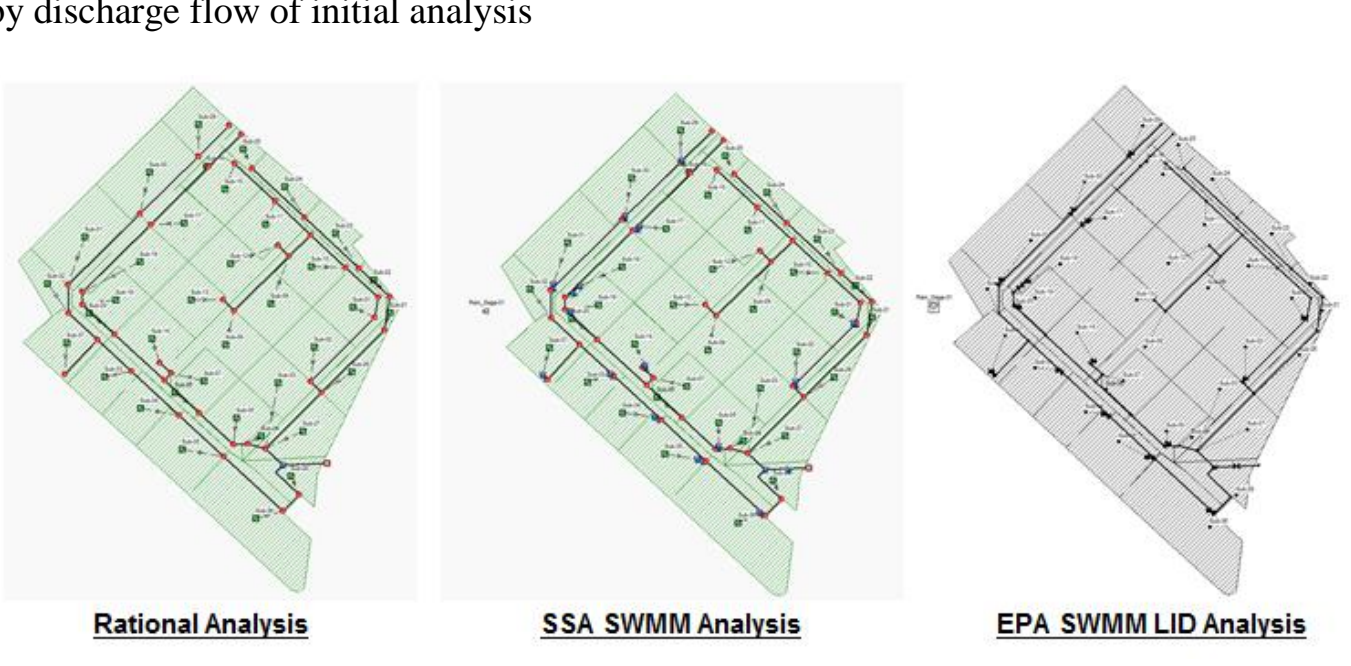

Figure 8. Study Location Analysis Model of SSA and EPA-SWMM
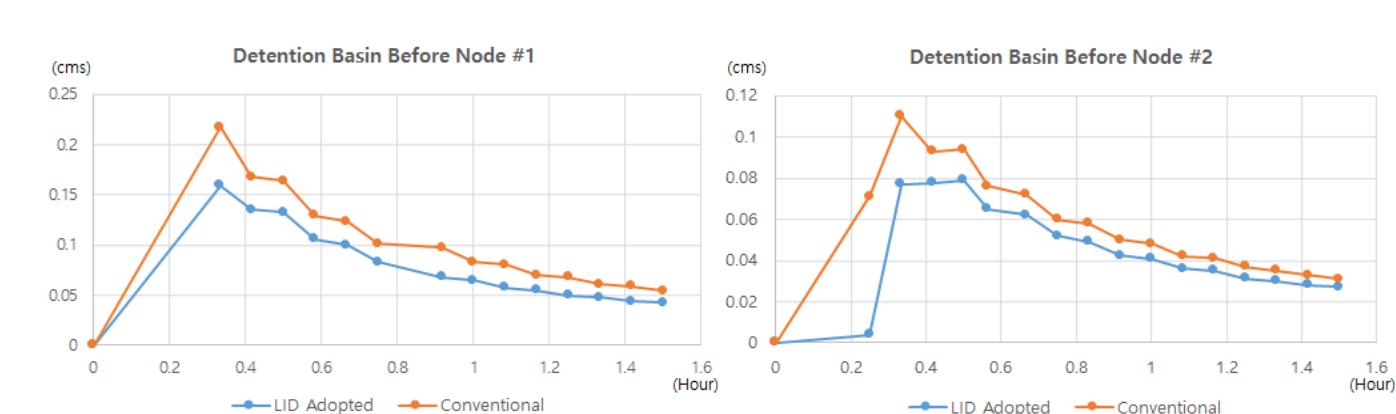

Figure 9. Study Location Analysis Result 


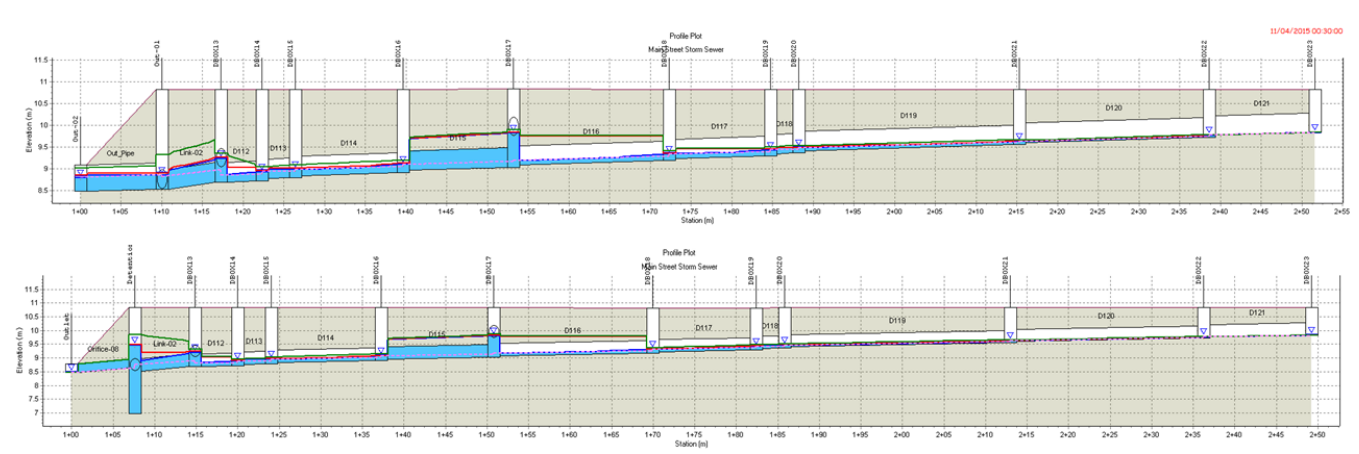

Figure 10. Profile of Study Location Storm Network

LID equipment can reduce up to $16.8 \sim 24.5 \%$ of the discharge flow and time to reach the maximum capacity of detention basin was 19.8 minutes. The project site drainage networks diameter was determined at $450 \mathrm{~mm}$ and most of the network pipes were reviewed as acceptable.

\section{Conclusion}

Most of engineer can use Autodesk ${ }^{\circledR}$ Revit platform but most of architect division engineer have any experience of Civil BIM platform. That is the why, data collaboration is limited to shape information based on 2D CADD software or use review software such as Autodesk ${ }^{\circledR}$ Navisworks. In this study, related divisions were able to engage in smooth design collaboration by exchanging the data code which is converted any data loss and tracking the revision data that was created in the seftware of individual sectors for townhouse BIM design and construction.

Additionally during the design process, the BIM model and information data was converted to analysis model data and exchanged with conventional analysis software without any data loss. This study concentrated on LID analysis based on the underground facility data exchange and mteroperable data by collaborating with related divisions.

However in the subsequent study, additional research into BIM data exchange of above-ground facilities will be conducted to acquire a higher interoperability of BIM data in different divisions from a practical siewpoint.

\section{Acknowledgements}

This work is sapported by the Korea Agency for Infrastructure Technology Advancement (KAIA) grant funded by the Ministry of Land, Infrastructure and Transport (Grant 1615007273).

\section{References}

[1] K. S. Ho, L. W. Jea, J. C. W and O. J. Ho, "A Study on the Revitalization for BIM in the Small Medium

Size Architectural Design Company", KICEM 2012-11, (2012), pp. 387-388.
12. D. Park and Y. W. Jeong, "A Study on the Ontology-Based Representation Model for Interoperability of BIM", vol. 26, no. 8, (2010) pp. 21-28.

[3] R. H. Kim, S. M. Park and H. D. Lee, "The Application Evaluation of Autodesk Storm and Sanitary Analysis for the Low Impact Development Design in the Park Area”, IJMUE_ITC-26, vol. 10, no. 10, (2015), pp. 167-176.

[4] S. J. Kwon, S. Lee, K. Choi and S. K. Jinman, "A Study of the Establishment of Framework for Information Exchange based on IFC Model in Domestic Collaborative Design Environment", KJCEM vol. 16, no. 1, (2015), pp. 24-34.

[5] L. M. Jae, P. H. Jin, Y. S. Ho, Koo and K. Jin, "Improvement Model of Design Coordination Process based on Analysis of Change Orders in Small-Scale Public Building Projects", AIK, vol. 25, no. 7, (2009), pp. 129-136.

[6] H. M. Bernstein, "The Business Value of BIM for Construction in Major Global Market", McGraw Hill Construction, (2014). 


\section{Authors}

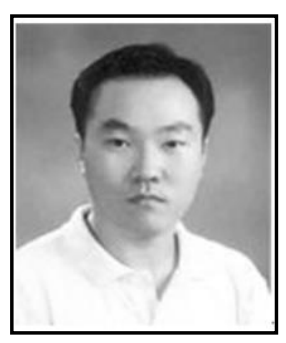

Sangmin Park, Damwon Co., Ltd. CEO, Seoul National University of Science and Technology. Department of Global Project Management Program. The Master's Course.

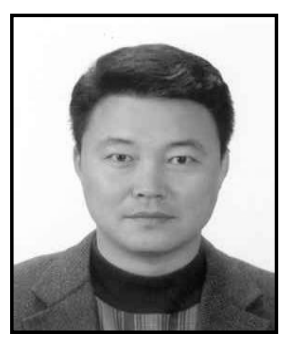

Reeho Kim, rhkim@kict.re.kr, Korea Institute of Civil Engineering and Building Technology, Environmental \& Plant Engineering Research Institute (EPRI). Senior Research Fellow: University of Science and Technology. Department of Construction Environment Engineering Professor. "Corresponding author.

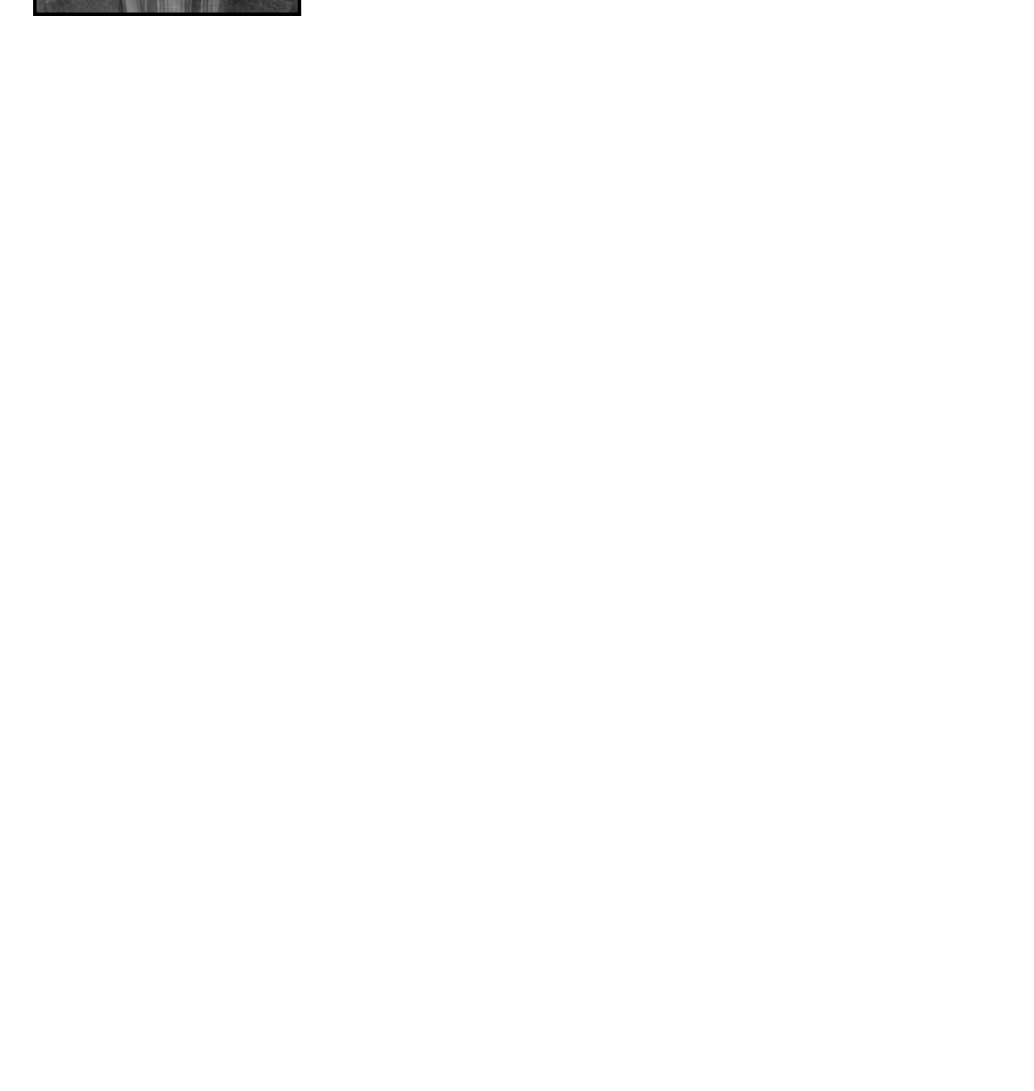


International Journal of Multimedia and Ubiquitous Engineering

Vol.11, No.11 (2016)

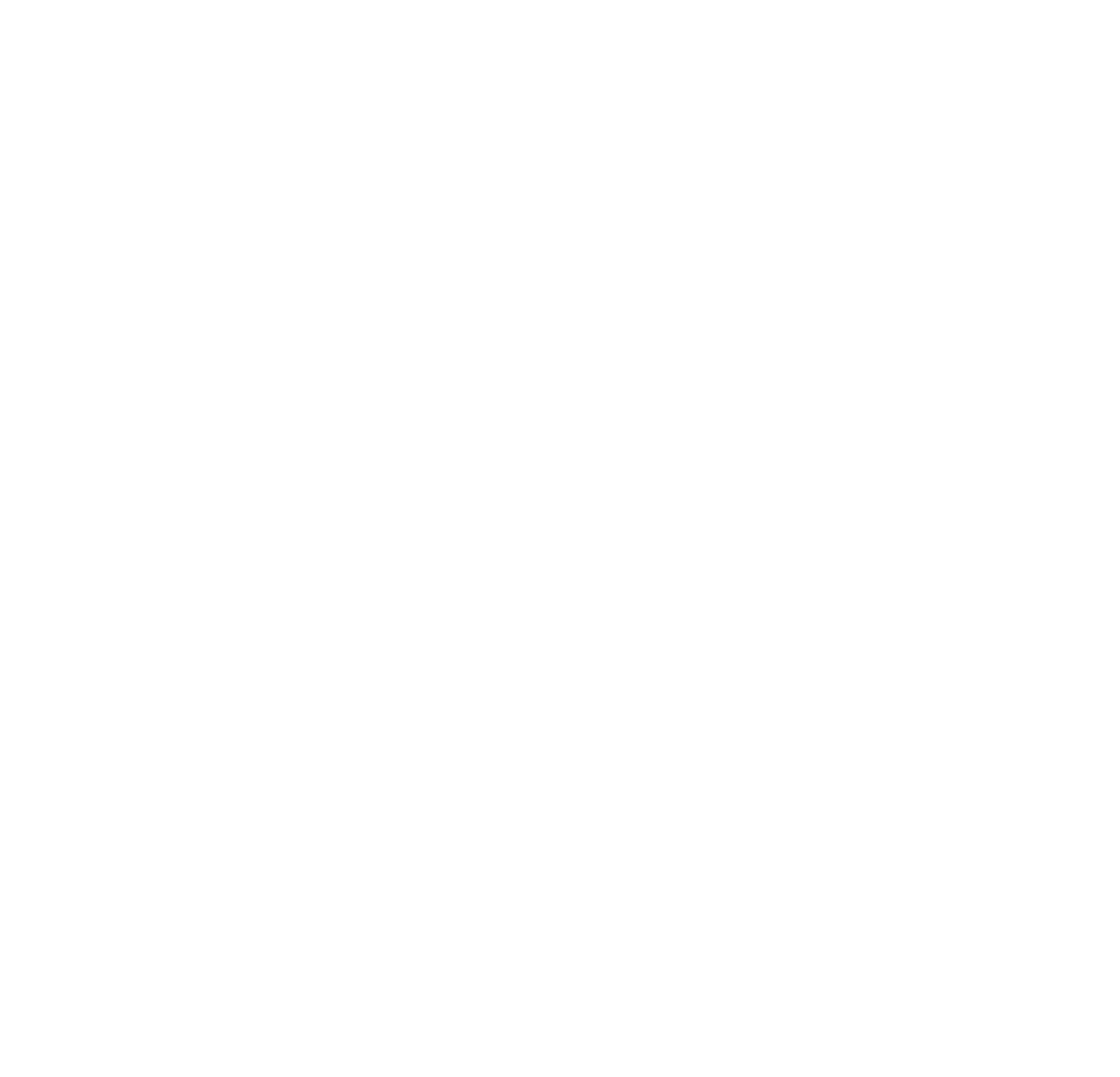

